\title{
The essential role of mentors in medical institutions
}

This article was published in the following Dove Press journal:

Advances in Medical Education and Practice

12 December 2016

Number of times this article has been viewed

\section{Arez Mohamed \\ Elena Antoni \\ University College London Medical School, University College London, London, UK}

Correspondence: Arez Mohamed 9I Upsdell Avenue, London NI36JJ, UK Tel +44796666 I937

Email arez.mohamed.II@ucl.ac.uk

\section{Dear editor}

We read with great interest the papers written by Al Qahtani ${ }^{1}$ and Banu et al. ${ }^{2}$ The former explored the motivation of medical students to engage in mentoring in a place where this was a scarce phenomenon and the other analyzed how mentoring could be successfully implemented and enhance acquisition of knowledge among mentees.

We would like to contribute in this field by providing our personal perspective of how mentoring came to represent a fundamental tool used by University College London (UCL) students like us and outline the opportunities we have throughout our studies to begin and establish relationships with various mentors. To enhance understanding of how the mentoring scheme is designed at UCL it is essential to acknowledge the presence of two distinct phases at UCL; the preclinical and the clinical phase. Mentoring is tailored according to the different educational requirements of each phase and individual's needs.

During the lecture-based preclinical phase ( 2 years), when commencing our studies as first-year students, we are greatly supported by our older colleagues, who become our mentors. Fifteen students are allocated per mentor. Here, we have the opportunity to gain basic information about the course but also form an initial support network that is crucial for increasing our confidence levels early on. Second, and perhaps more importantly, each of us is allocated a "medic mum and dad," which are a male and a female student from the year above. They essentially provide guidance on any academic or nonacademic issues that first-year students might need help with. The mentees meet their group mentor up to once a month but meet their medic "mum and dad" up to once a week.

Both of these mentoring schemes have proven beneficial for both the mentor and mentee in numerous ways. In the case of the mentoring group, the mentor acts as an anchoring system to unite his mentees and inspires them to form closer relationships that may be difficult to accomplish otherwise due to the increasing responsibilities of each student and variation in timetable and classes. The mentor in this case is also a more mature student who has already experienced the challenges of being a first-year medical student and remembers the overwhelming feeling that can be generated in the first year.

The "Medic Parents" scheme benefits the mentees further by allowing them to build a lasting rapport with their medic parents in an informal and comfortable setting. This usually involves organizing both educational and social activities, greatly improving submit your manuscript Dovepress if in $D$ 
the mentees ability to integrate with peers while feeling safe under the supervision of their medic parents. The mentors' benefit by gaining experience in educating, organizing, and managing their younger peers, while it is also highly rewarding for them to contribute to the professional and personal development of a future colleague.

When entering the clinical phase of medicine that is orientated toward a hospital setting, mentors comprise of students within the medical school and doctors in the hospital. For example, during the first clinical module, the final-year mentors formally teach mentees the skills to perform core examinations. Junior doctors from within the teaching hospitals are assigned to be "twilight tutors" for three or four students each. They teach mentees a medical topic and mentor them during these sessions.

While having slightly different roles compared to the mentors in the preclinical phase, they have the vital task of helping medical students progress smoothly into good clinicians. Both final-year students and twilight tutors are great examples of the professional standard that mentees should be aiming to achieve. Starting clinical years can be a daunting prospect when considering the amount of medical information that has to be learned, but having young mentors who can easily empathize with the difficulties a student experiences during the transition from preclinical into the clinical phase allows the mentee to express comfortably his thoughts and worries. As final-year students, we still have contact with our twilight mentors who we appreciate for alleviating our stresses at the time.

In conclusion, we greatly advocate the use of mentors throughout medical school. As demonstrated through our examples, mentors adopt a holistic approach when providing their fellow medical students with educational and emotional support, while also gaining valuable leadership and communication skills through mentoring. We agree that having these mentors throughout our time at UCL has significantly transformed our journey through the two phases, and hence we highly encourage their implementation in all medical institutions.

\section{Disclosure}

The authors report no conflicts of interest in this communication.

\section{References}

1. Al Qahtani S. Students' knowledge of, and attitudes toward, mentoring: a case study at the Master's Program in Health and Hospital Administration. Adv Med Educ Pract. 2015;6:149-152.

2. Banu S, Juma FZ, Abas T. Mentoring in higher education. Adv Med Educ Pract. 2016;7:523-525.

Dove Medical Press encourages responsible, free and frank academic debate. The content of the Advances in Medical Education and Practice 'letters to the editor' section does not necessarily represent the views of Dove Medical Press, its officers, agents, employees, related entities or the Advances in Medical Education and Practice editors. While all reasonable steps have been taken to confirm the content of each letter, Dove Medical Press accepts no liability in respect of the content of any letter, nor is it responsible for the content and accuracy of any letter to the editor.

\section{Publish your work in this journal}

Advances in Medical Education and Practice is an international, peerreviewed, open access journal that aims to present and publish research on Medical Education covering medical, dental, nursing and allied health care professional education. The journal covers undergraduate education, postgraduate training and continuing medical education including emerging trends and innovative models linking education, research, and health care services. The manuscript management system is completely online and includes a very quick and fair peer-review system. Visit http://www.dovepress.com/testimonials.php to read real quotes from published authors. 